\title{
Odontoid process inclination in normal adults and in an adult population with Chiari malformation Type I
}

\author{
David A. Besachio, D0,,2 Ziyad Khaleel, MBChB,3,4 and Lubdha M. Shah, MD1 \\ ${ }^{1}$ Department of Radiology, University of Utah, Salt Lake City, Utah; ${ }^{2}$ US Naval Medical Center Portsmouth, Virginia; ${ }^{3}$ Royal Perth \\ Hospital, Perth; and ${ }^{4}$ Sir Charles Gairdner Hospital, Nedlands, Western Australia, Australia
}

\begin{abstract}
OBJECT Posterior odontoid process inclination has been demonstrated as a factor associated with Chiari malformation Type I (CM-I) in the pediatric population; however, no studies to date have examined this measurement in the adult CM-I population. The purpose of this study was to evaluate craniocervical junction (CCJ) measurements in adult CM-I versus a control group.
\end{abstract}

METHODS The odontoid retroflexion, odontoid retroversion, odontoid height, posterior basion to C-2 line measured to the dural margin (pB-C2 line), posterior basion to $\mathrm{C}-2$ line measured to the dorsal odontoid cortical margin (pB-C2* line), and clivus-canal angle measurements were retrospectively analyzed in adult patients with $\mathrm{CM}-\mathrm{I}$ using MRI. These measurements were compared with normative values established from CT scans of the cervical spine in adults without CM-I.

RESULTS A statistically significant difference was found between 55 adults with CM-I and 150 sex-matched controls (125 used for analysis) in the mean clivus-canal angle and the mean pB-C2 line.

CONCLUSIONS These data suggest that there are sex-specific differences with respect to measurements at the CCJ between men and women, with women showing a more posteriorly inclined odontoid process. There were also differences between the $\mathrm{CM}-\mathrm{I}$ and control groups: a more acute clivus-canal angle was associated with $\mathrm{CM}-\mathrm{I}$ in the adult population. These CCJ findings could have an influence on presurgical planning.

http://thejns.org/doi/abs/10.3171/2015.3.SPINE14926

KEY WORDS odontoid inclination; Chiari malformation; complex Chiari malformation; cervical; craniocervical junction

$\mathrm{C}$ HIARI malformation Type I (CM-I) is a disorder of the paraxial mesoderm resulting in an underdeveloped posterior cranial fossa and subsequent hindbrain crowding with potential CSF abnormalities. ${ }^{13}$ This is classically defined as downward herniation of the cerebellar tonsils through the foramen magnum and was initially described in the late 1800 s by Hans Chiari. ${ }^{10}$ Advances in imaging have led to significant insight into the investigation of CM-I and its management. ${ }^{12}$ Although posterior decompression for symptomatic CM-I is the current treatment standard, a subset of patients with significant ventral cervicomedullary compression has raised the question of whether ventral decompression with or without posterior fusion should be considered in the CM-I population. ${ }^{6,17}$ There has been recent interest regarding the impact of posterior odontoid inclination in CM-I, and radiographic studies in the pediatric population have demonstrated an association between CM-I and posterior odontoid inclination. ${ }^{20}$ Normative values for odontoid inclination in the adult population have only recently been established. ${ }^{8}$ There has been no comparative evaluation for odontoid inclination between patients with CM-I and the normal adult population. The purpose of this study is to examine the craniocervical junction (CCJ) in the normal adult population compared with the CM-I population, and its potential relationship to presurgical planning.

\section{Methods Study Population}

Following institutional review board approval, the authors retrospectively analyzed noncontrasted cervical

ABBREVIATIONS CCJ = craniocervical junction; $\mathrm{CM}=$ Chiari malformation; $\mathrm{CM}-\mathrm{I}=\mathrm{CM}$ Type I; ICC = intraclass correlation coefficient; $\mathrm{pB}-\mathrm{C} 2=\mathrm{a}$ line drawn through the odontoid tip from the ventral dura perpendicular to a second line from the basion to the inferoposterior aspect of the $\mathrm{C}-2$ vertebral body; $\mathrm{pB}-\mathrm{C} 2^{*}=\mathrm{a}$ line drawn through the odontoid tip from the posterior odontoid cortex perpendicular to a second line from the basion to the inferoposterior aspect of the C-2 vertebral body.

SUBMITTED November 8, 2014. ACCEPTED March 26, 2015.

INCLUDE WHEN CITING Published online August 28, 2015; DOI: 10.3171/2015.3.SPINE14926. 
spine CT scans of adult patients (age $>18$ years) that were obtained for indications not related to CM-I. ${ }^{8}$ Computed tomography was performed on a 64-section scanner (Siemens) with a helical acquisition and 0.6-mm collimation. All CT scans were reviewed in the sagittal plane in bone and soft tissue algorithms. In this study, adult patients with CM-I and clinical examination and MRI findings consistent with the diagnosis of CM-I, who underwent suboccipital decompression, were identified from neurosurgical clinic records. Thorough histories, and physical and neurological examinations, were obtained in these CM-I patients, which formed the basis of the diagnosis. Symptomatic CM-I was diagnosed based on the presence or absence of the following clinical signs and symptoms: cervical syringohydromyelia, occipital or Valsalva maneuver-induced headaches, and neck or back pain. ${ }^{7}$ A review of the electronic medical records, however, revealed no specific clinical documentation of neurological symptoms to suggest cervicomedullary compression, such as swallowing difficulty, or myelopathic symptoms, including hyperreflexia, spasticity, and/or positive Babinski sign..$^{15,22}$

\section{Imaging Parameters}

Preoperative MRI of the cervical spine for these adult patients with a diagnosis of CM-I was retrospectively evaluated. All MRI was performed on a 1.5-T scanner (Avanto or Aera, Siemens) or 3.0-T scanner (Verio, Siemens). Sagittal T1-weighted inversion recovery and T2-weighted images were reviewed (T1-weighted inversion recovery $=3-\mathrm{mm}$ slice thickness, TR $2000 \mathrm{msec}$, TE $20 \mathrm{msec}$, TI $830 \mathrm{msec}$, FOV $22 \mathrm{~cm}$; T2-weighted inversion recovery = 3-mm slice thickness, TR 3000-6000 msec, TE $112 \mathrm{msec}$, FOV $22 \mathrm{~cm}$ ). Sagittal T1-weighted images were used to obtain the measurements and sagittal T2-weighted images were used to evaluate for cervicomedullary compression and edema. The imaging criterion for CM-I was tonsillar extension $5 \mathrm{~mm}$ or more below the foramen magnum on sagittal MRI. Patients with osseous injury, mass lesions, extensive arthropathy that distorted normal anatomy, or congenital abnormalities of the CCJ were excluded from the analysis.

\section{Radiological Measurement}

Six measurements of the CCJ were carried out by 3 neuroradiologists for each control patient (D.A.B., Z.K., and L.M.S.), and then were averaged. ${ }^{8}$ The 3 readers for the normal CT craniocervical measurements had substantial interrater reliability and together established specific imaging criteria. ${ }^{8}$ In the current study, 2 neuroradiologists used these specific criteria while making the measurements on the CM-I group, and their measurements were averaged. The purpose of this portion of the study was to evaluate the various CCJ measurements in the adult CM-I population. The first measurement was the odontoid retroversion angle (Figs. 1A and 2B). The second measurement was the odontoid retroflexion angle (Figs. 1B and 2A). The third measurement was odontoid process height (Figs. 1C and $2 \mathrm{C}$ ). The fourth measurement was the clivus-canal angle (Figs. 1D and 2F). The fifth and sixth measurements were the $\mathrm{pB}^{-\mathrm{C} 2} *$ and $\mathrm{pB}-\mathrm{C} 2$ lines, measured as a line
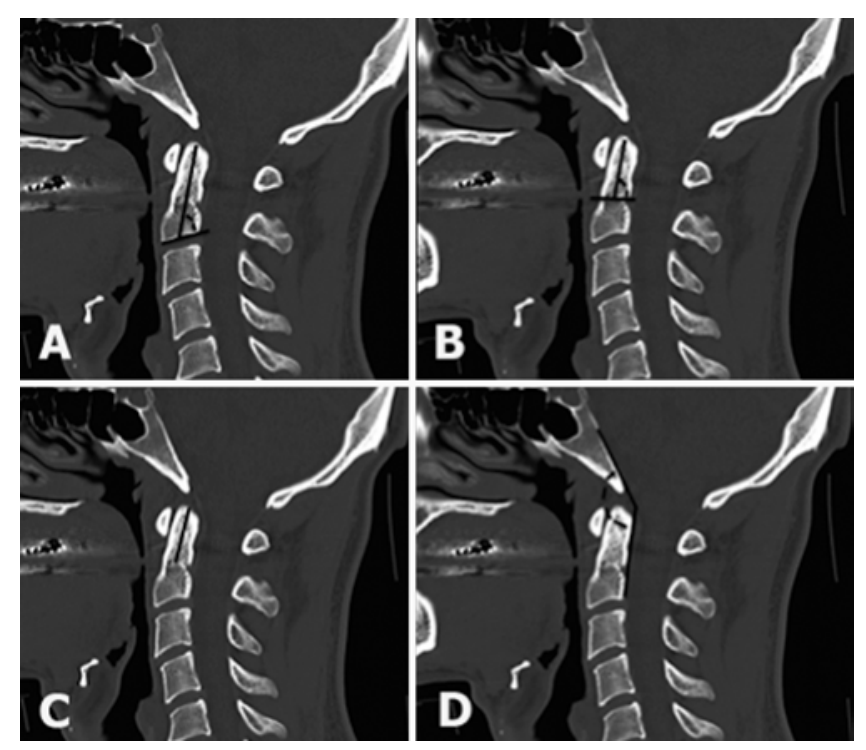

FIG. 1. Sagittal CT images in control patients demonstrating the odontoid retroversion angle (A), odontoid retroflexion angle (B), odontoid height (C), and clivus-canal angle (D).

drawn through the odontoid tip from the posterior odontoid cortex perpendicular to a second line from the basion to the inferoposterior aspect of the C-2 vertebral body (pB-C2*; Fig. 2E) or a line drawn through the odontoid tip from the ventral dura perpendicular to a second line from the basion to the inferoposterior aspect of the C-2 vertebral body (pB-C2; Fig. 2D).

Postoperative records of the patients with CM-I were reviewed up to 12 months following suboccipital craniectomy. Treatment success was considered as a clinically significant reduction or resolution of symptoms resulting from the previous diagnosis of CM-I; specifically, resolution of occipital headaches and neck pain. The clinical records were reviewed for specific documentation of myelopathy related to cervicomedullary compression on follow-up clinical records up to 12 months postoperatively.

\section{Statistical Analysis}

Statistical analysis was undertaken using 2-tailed, paired t-tests for each measurement between the normal adult control and CM-I patient and statistical significance was set at $p$ values $<0.05$. The intraclass correlation coefficient (ICC) was interpreted as the proportion of total variability in measurements due to subject variability (coefficient value $>0.75$ considered excellent, 0.6-0.74 considered good, $0.4-0.59$ fair, and $<0.4$ poor). Statistical analysis was performed using Stata (version 13, StataCorp). Means are presented \pm SD.

\section{Results}

In the control group, of the 150 patients evaluated, 125 met criteria for inclusion in the study. ${ }^{8}$ Of these patients, 80 were male and 45 were female, with ages ranging from 18 to 89 years old (mean $52 \pm 18.5$ years old). The odontoid retroflexion angle was used as a measure of interrater agreement in the control group and demonstrated good interrater agreement between neuroradiologists. ${ }^{1}$ The ICC 

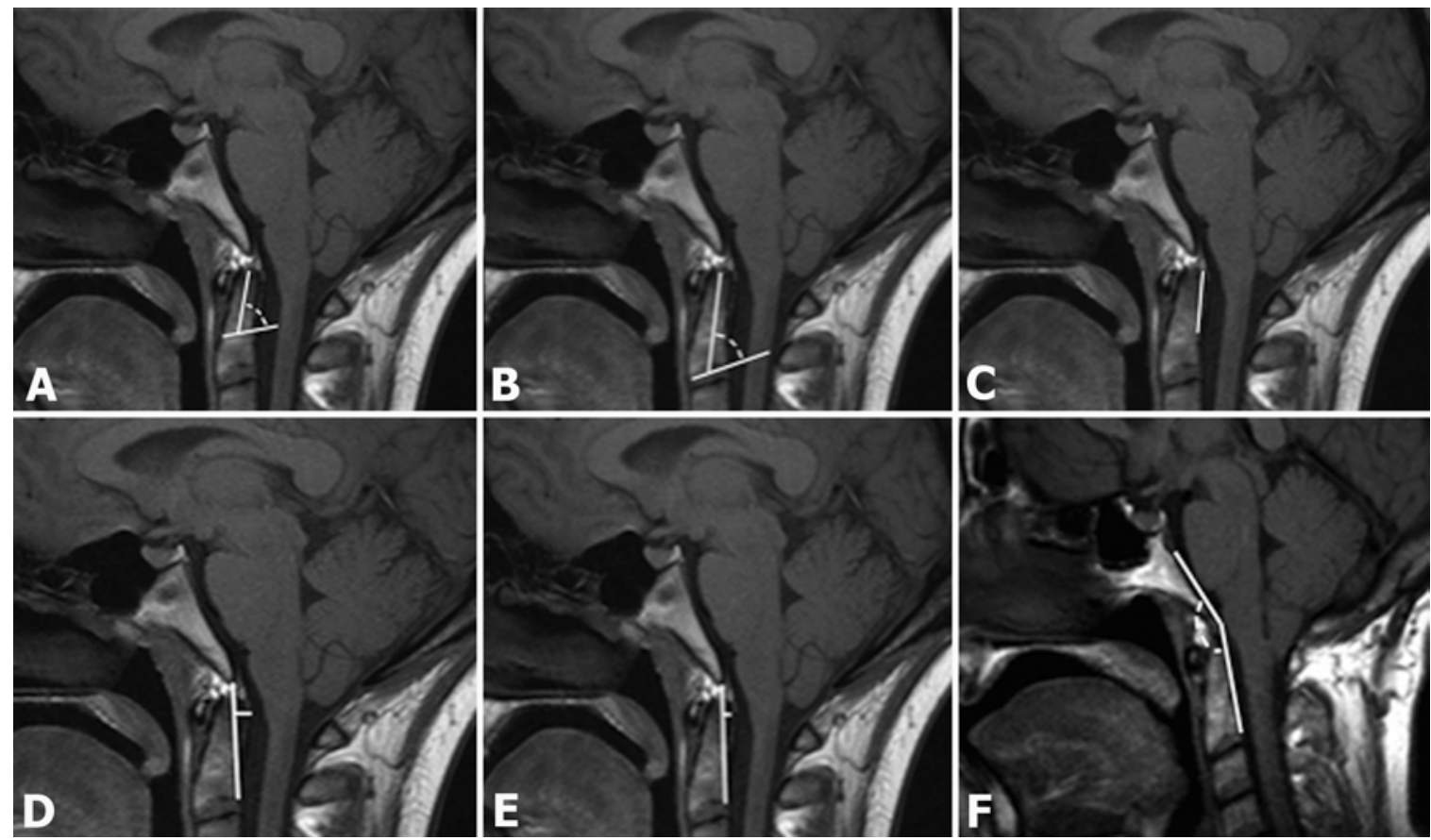

FIG. 2. Sagittal T1-weighted MR images in a patient with CM-I demonstrate the odontoid retroflexion angle (A), odontoid retroversion angle (B), odontoid height (C), pB-C2 line (perpendicular length between a line connecting the basion and the inferoposterior $\mathrm{C}-2$ body to the ventral dural; (D), pB-C2* line (perpendicular length between a line connecting the basion and the inferoposterior $\mathrm{C} 2$ body to the posterior odontoid cortex; (E), and clivus-canal angle (F).

for the retroflexion angle was $0.69-0.7$ between readers. The difference between measurements for any pair of readers did not reach statistical significance $(\mathrm{p}>0.05$, paired 2-tailed t-test).

Values differed significantly between males and females in the control group for odontoid retroflexion angle (mean $79.9^{\circ} \pm 4.9^{\circ}$ for males, mean $78^{\circ} \pm 4.8^{\circ}$ for females, $\mathrm{p}=0.048$ ), odontoid retroversion angle (mean $72.9^{\circ} \pm 5.7^{\circ}$ for males, mean $70^{\circ} \pm 4^{\circ}$ for females; $p=0.002$ ), odontoid process height (mean $22.7 \pm 1.7 \mathrm{~mm}$ for males, mean $21.2 \pm 1.5 \mathrm{~mm}$ for females; $\mathrm{p}=0.0002$ ), and $\mathrm{pB}-\mathrm{C} 2$ length (mean $6.7 \pm 2.2 \mathrm{~mm}$ for males, mean $6 \pm 2 \mathrm{~mm}$ for females; $\mathrm{p}=0.03$; Table 1). A clivus-canal angle of $<150^{\circ}$ was found in 8 control patients.

Of the 55 patients with CM-I identified as meeting neurosurgical criteria for CM-I, all met criteria for inclusion in the study. Of these patients, 18 were male and 37 were female, with ages ranging from 18 to 61 years old (mean $34 \pm 10.2$ years old).

\section{TABLE 1. CCJ measurements in control patients according to} sex

\begin{tabular}{lccl}
\hline \multicolumn{1}{c}{ Parameter } & $\begin{array}{c}\text { Control Men } \\
(\mathrm{n}=80)\end{array}$ & $\begin{array}{c}\text { Control Women } \\
(\mathrm{n}=45)\end{array}$ & $\begin{array}{c}\mathrm{p} \text { Value } \\
(\mathrm{t} \text {-test })\end{array}$ \\
\hline Odontoid retroflexion $\left(^{\circ}\right)$ & $79.9 \pm 4.9$ & $78 \pm 4.8$ & 0.048 \\
\hline Odontoid retroversion $\left(^{\circ}\right)$ & $72.9 \pm 5.7$ & $70 \pm 4$ & 0.002 \\
\hline Clivus-canal angle $\left(^{\circ}\right)$ & $164.8 \pm 10.4$ & $163.7 \pm 10$ & 0.26 \\
\hline Odontoid height $(\mathrm{mm})$ & $22.7 \pm 1.7$ & $21.2 \pm 1.5$ & 0.0002 \\
\hline $\mathrm{pB}-\mathrm{C2}{ }^{*}(\mathrm{~mm})$ & $4.3 \pm 2$ & $4 \pm 1.7$ & 0.15 \\
\hline $\mathrm{pB}-\mathrm{C} 2(\mathrm{~mm})$ & $6.7 \pm 2.2$ & $6 \pm 2$ & 0.03 \\
\hline
\end{tabular}

When comparing all controls to all patients with CM-I, there were significant differences in all measured parameters with the exception of $\mathrm{pB}-\mathrm{C} 2 *$ (Table 2). The CM-I group had smaller retroflexion and retroversion angles, had greater $\mathrm{pB}-\mathrm{C} 2$ values, and shorter odontoid heights. Among the male cohort, a significant difference between the control group and the CM-I group was found with the mean clivus-canal angle (mean $164.9^{\circ} \pm 10.4^{\circ}$ in the control group vs $155.4^{\circ} \pm 10.9^{\circ}$ in the CM-I group; $\mathrm{p}=0.007$ ) and odontoid height (mean $22.6 \pm 1.7 \mathrm{~mm}$ in the control group vs $21.1 \pm 1.6 \mathrm{~mm}$ in the CM-I group; $\mathrm{p}=0.008$; Table 3). Among the female cohort, a significant difference between the control group and the CM-I group was found with odontoid retroversion (mean $70^{\circ} \pm 4^{\circ}$ in the control group vs $67.7^{\circ} \pm 3.8^{\circ}$ in the CM-I group; $\mathrm{p}=0.01$ ), clivus-canal angle (mean $163.7^{\circ} \pm 9.9^{\circ}$ in the control group vs $157.4^{\circ} \pm 7.2^{\circ}$ in the CM-I group; $p=0.002$ ), odontoid height (mean $21.1 \pm 1.5 \mathrm{~mm}$ in the control group vs 20.2 $\pm 1.6 \mathrm{~mm}$ in the $\mathrm{CM}-\mathrm{I}$ group; $\mathrm{p}=0.009$ ), and $\mathrm{pB}-\mathrm{C} 2$ line

TABLE 2. CCJ measurements in controls versus patients with CM-I

\begin{tabular}{lcrr}
\hline \multicolumn{1}{c}{ Parameter } & $\begin{array}{c}\text { Normal Adult } \\
\text { Cohort }(n=125)\end{array}$ & CM-I $(n=55)$ & $\begin{array}{r}\text { p Value } \\
(\mathrm{t} \text {-test })\end{array}$ \\
\hline Odontoid retroflexion $\left(^{\circ}\right)$ & $79.2 \pm 4.9$ & $77 \pm 4.2$ & 0.016 \\
\hline Odontoid retroversion $\left(^{\circ}\right)$ & $71.8 \pm 5.3$ & $68.6 \pm 3.8$ & $<0.001$ \\
\hline Clivus-canal angle $\left(^{\circ}\right)$ & $164.5 \pm 10.2$ & $156.8 \pm 8.3$ & $<0.001$ \\
\hline Odontoid height $(\mathrm{mm})$ & $22.1 \pm 1.8$ & $20.5 \pm 1.6$ & $<0.001$ \\
\hline pB-C2 ${ }^{*}(\mathrm{~mm})$ & $4.2 \pm 1.9$ & $4.3 \pm 1.1$ & 0.66 \\
\hline pB-C2 $(\mathrm{mm})$ & $6.5 \pm 2.2$ & $7.2 \pm 1.5$ & 0.03 \\
\hline
\end{tabular}


TABLE 3. CCJ measurements in male controls versus males with CM-I

\begin{tabular}{lccl}
\hline & \multicolumn{2}{c}{ Males } & \\
\cline { 2 - 3 } \multicolumn{1}{c}{ Parameter } & Controls $(\mathrm{n}=80)$ & $\mathrm{CM}-\mathrm{I}(\mathrm{n}=18)$ & $\begin{array}{l}\text { p Value } \\
(\mathrm{t} \text {-test })\end{array}$ \\
\hline Odontoid retroflexion $\left(^{\circ}\right)$ & $79.9 \pm 4.9$ & $78.1 \pm 4.7$ & 0.15 \\
\hline Odontoid retroversion $\left(^{\circ}\right)$ & $72.9 \pm 5.7$ & $70.3 \pm 4.3$ & 0.07 \\
\hline Clivus-canal angle $\left.^{\circ}{ }^{\circ}\right)$ & $164.9 \pm 10.4$ & $155.4 \pm 10.9$ & 0.007 \\
\hline Odontoid height $(\mathrm{mm})$ & $22.6 \pm 1.7$ & $21.1 \pm 1.6$ & 0.008 \\
\hline pB-C2* $(\mathrm{mm})$ & $4.4 \pm 2.1$ & $4.3 \pm 1.9$ & 0.95 \\
\hline $\mathrm{pB}-\mathrm{C} 2(\mathrm{~mm})$ & $6.7 \pm 2.2$ & $7.1 \pm 1.6$ & 0.5 \\
\hline
\end{tabular}

length (mean $6 \pm 2 \mathrm{~mm}$ in the control group vs $7.2 \pm 1.4$ $\mathrm{mm}$ in the CM-I group; $\mathrm{p}=0.003$; Table 4). A clivus-canal angle of $<150^{\circ}$ was found in a total of 10 patients with CM-I. Comparing male and female patients with CM-I, there was no significant difference in the $\mathrm{pB}-\mathrm{C} 2(\mathrm{p}=0.4)$ and $\mathrm{pB}-\mathrm{C} 2 *(\mathrm{p}=0.44)$ lengths.

For the CM-I group, the ICCs were highest for the clivus-canal angle (0.66) and the pB-C2 length (0.66). The ICCs for odontoid retroversion angle $(0.45), \mathrm{pB}-\mathrm{C} 2 *$ line $(0.49)$, and odontoid process length $(0.46)$ were fair, while the retroflexion ICC was poor (0.34).

None of the patients with CM-I demonstrated clinical or imaging evidence of myelopathy, nor was any spinal cord signal abnormality identified to suggest edema or venous congestion from cord compression. None of the patients with CM-I demonstrated a syrinx on imaging. All patients with CM-I demonstrated treatment success within 6 months of suboccipital decompression based on record review of the clinical examination. None of the patients with CM-I developed delayed symptoms of cervicomedullary compression on follow-up clinical records up to 12 months postoperatively.

\section{Discussion}

Although posterior decompression alone for CM-I is often successful in alleviation of CM-associated symptoms, pediatric, and more recently adult, literature has suggested that a small subset of patients may require ventral decompression secondary to cervicomedullary compression from CCJ abnormalities. ${ }^{17,18,20}$ Some pediatric studies have suggested that excessive odontoid retroflexion associated

TABLE 4. CCJ measurements in female controls versus females with $\mathrm{CM}-\mathrm{I}$

\begin{tabular}{lcrl}
\hline & \multicolumn{2}{c}{ Females } & \\
\cline { 2 - 3 } \multicolumn{1}{c}{ Parameter } & Controls $(\mathrm{n}=45)$ & $\mathrm{CM}-\mathrm{I}(\mathrm{n}=37)$ & $\begin{array}{c}\mathrm{p} \text { Value } \\
\text { (t-test) }\end{array}$ \\
\hline Odontoid retroflexion $\left(^{\circ}\right)$ & $78.01 \pm 4.8$ & $77 \pm 4.6$ & 0.28 \\
\hline Odontoid retroversion $\left(^{\circ}\right)$ & $70 \pm 4$ & $67.7 \pm 3.8$ & 0.01 \\
\hline${\text { Clivus-canal angle }\left(^{\circ}\right)}^{\circ}$ & $163.7 \pm 9.9$ & $157.4 \pm 7.2$ & 0.002 \\
\hline Odontoid height $(\mathrm{mm})$ & $21.1 \pm 1.5$ & $20.2 \pm 1.6$ & 0.009 \\
\hline pB-C2 $(\mathrm{mm})$ & $3.99 \pm 1.7$ & $4.4 \pm 1.0$ & 0.25 \\
\hline pB-C2 $(\mathrm{mm})$ & $6 \pm 2$ & $7.2 \pm 1.4$ & 0.003 \\
\hline
\end{tabular}

with an increase in the $\mathrm{pB}-\mathrm{C} 2$ line value is a causative factor in ventral cervicomedullary compression in the CM-I population. ${ }^{20}$ Understanding how this measurable value, as well as other CCJ measurements, differs in the CM-I population relative to controls is an important data point. Measurement of odontoid inclination in normal adults differs from published data for the pediatric population; in adults, the odontoid is more posteriorly inclined than that observed in the pediatric CM-I population. ${ }^{8}$ Our grouped data comparing all control patients to all CM-I patients would suggest significant differences in nearly all measured parameters at the CCJ. However, based on analysis of control group data, there are significant differences in CCJ measurements between males and females, with female odontoid processes demonstrating greater posterior inclination and shorter length than their male counterparts. These data suggest that, in addition to utilizing differing normative values for the CCJ for the adult versus pediatric population, sex-specific norms should also be considered. ${ }^{8}$ When comparing adult sex-specific controls to their adult CM-I counterparts, our data do not support the pediatric literature that a correlation exists between increased retroflexion and CM-I. ${ }^{20}$ The retroflexion measure was found to be a more accurate assessment of odontoid angulation as compared with retroversion, because of less variation in the base of the C-2 vertebral body. ${ }^{20}$ There was a similarity in retroflexion values for the CM-I group as reflected by the low ICC. The higher ICC value for retroflexion in the normal controls implies a greater degree of variability in the control group. ${ }^{19}$

In the adult CM-I group, the odontoid height is shorter, the $\mathrm{pB}-\mathrm{C} 2$ value is significantly larger, and the clivuscanal angle is more acute when compared with controls. The shortened odontoid height in the CM-I group may reflect the underlying malformation of the axial component of the occipital sclerotome, proatlas, and C-1 resegmented sclerotome, resulting in odontoid and basiocciput dysgenes. ${ }^{14}$ Only the $\mathrm{pB}-\mathrm{C} 2$ value reaches significance in our cohort as opposed to the $\mathrm{pB}-\mathrm{C} 2 *$ value (a line extending to the posterior cortical margin of the odontoid process, not inclusive of the ventral dura). This finding persists in subgroup analysis of female patients (Table 4). A larger $\mathrm{pB}-\mathrm{C} 2$ value in this setting reflects a greater amount of peri-odontoid tissue, also referred to as the "crown," and not increased odontoid posterior inclination. ${ }^{17}$ Increased peri-odontoid tissue is more often observed in the aged population; however, the mean age of our CM-I population was only 34 years. Menezes postulated that skull base hypoplasia may contribute to ligamentous laxity at the CCJ with subsequent granulation tissue proliferation. ${ }^{11}$ Support for this hypothesis is suggested through stabilizing procedures that have demonstrated a postoperative decrease in the prominence of this tissue. ${ }^{21}$ Although speculative, it has also been suggested that the relative instability between the cerebellar tonsils and the foramen magnum (because of the small posterior fossa) with intermittent block of CSF flow contributes to ligamentous enlargement, which may be reflected in a larger amount of peri-odontoid tissue. ${ }^{6}$

Established craniovertebral junction measurements state that a clivus-canal angle $<150^{\circ}$ is abnormal regard- 
less of patient positioning, and at angles $<150^{\circ}$ there is a known increased risk of ventral cervical spinal cord compression. ${ }^{18} \mathrm{~A}$ decrease in the clivus-canal angle is a described feature of basilar invagination, a developmental finding associated with basiocciput hypoplasia. ${ }^{18}$ This < $150^{\circ}$ measurement was present in only $6.4 \%$ of our control group but $18.2 \%$ of our CM-I group (Fig. 3). The overall significantly increased acuity of the clivus-canal angle in the CM-I group suggests a trend toward a shortened basiocciput, which in conjunction with increased peri-odontoid tissue, may predispose this group to an increased risk of ventral cervical spinal cord compression in the absence of increased odontoid inclination. However, none of our patients demonstrated physical examination abnormalities or abnormal cervicomedullary T2-weighted signal abnormality to suggest cord compression. Direct assessment of basilar invagination or platybasia through evaluation of the McGregor line or Welcher basal angle was not undertaken in this review. However, in the absence of a statistically significant sex-adjusted difference in odontoid retroflexion between CM-I patients and control subjects, it may be suggested that the trend of a more acute clivus-canal angle in the CM-I group is secondary to flattening of the clivus. This flattening is an indirect measure of platybasia and basilar invagination, two entities that are not infrequently observed in association with one another. ${ }^{9}$

In the pediatric population, Grabb et al. have suggested that patients with a significantly lengthened pB-C2 distance $(>9 \mathrm{~mm})$ may benefit from traction or transoral odontoidectomy prior to standard CM decompression. ${ }^{4}$ Given the differences between the adult and the pediatric populations and the differences between male and female patients, the decision of whether to perform odontoidectomy or traction with posterior fusion may be not only agebut also sex-specific. Nine of our patients with CM-I had $\mathrm{pB}-\mathrm{C} 2$ values greater than $9 \mathrm{~mm}$ and did not demonstrate a difference from those patients with a $\mathrm{pB}-\mathrm{C} 2$ value less than $9 \mathrm{~mm}$, with respect to success of standard suboccipital decompression. With higher rates of CM-I diagnosis due to advances in imaging, more precise stratification
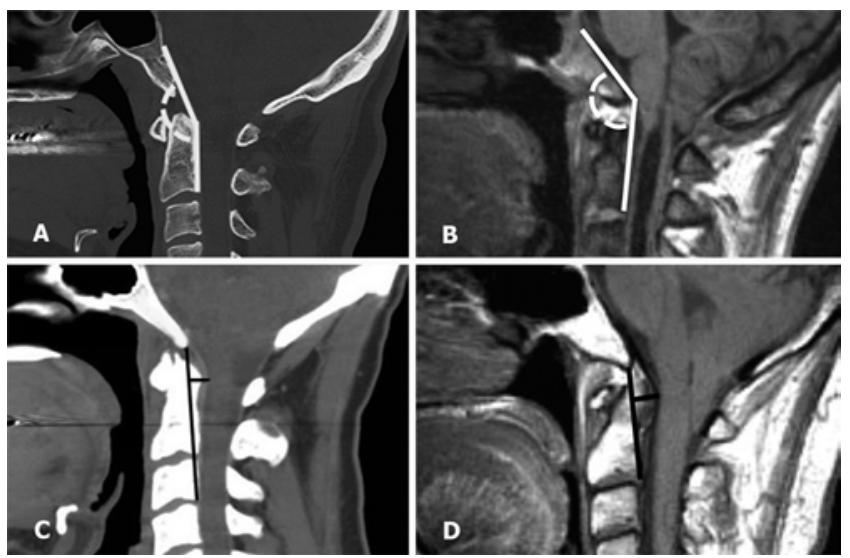

FIG. 3. Sagittal CT image in bone algorithm (A) demonstrates a normal clivus-canal angle as compared with a sagittal T1-weighted image (B) in a CM-I patient with a clivus-canal angle of $140^{\circ}$. Sagittal CT image in soft-tissue algorithm (C) shows a normal control pB-C2 measurement and a sagittal T1-weighted image (D) shows a pB-C2 length of $9 \mathrm{~mm}$ in a patient with $\mathrm{CM}-\mathrm{I}$. of patients into those who can be successfully managed conservatively versus those who will need standard suboccipital decompression or more aggressive surgical intervention for good clinical outcome should be evaluated in light of these findings. ${ }^{6}$ All of our adult patients with CM-I underwent suboccipital decompression with varying degrees of C-1 and C-2 laminectomy and duraplasty. None of these adult patients had symptoms related to cervicomedullary compression that required odontoid resection in the first 6-12 months of postoperative follow-up. Others have demonstrated improvement of symptoms due to cervicomedullary compression with posterior fossa decompression alone. ${ }^{17}$

When symptomatic, CM-I is usually treated by suboccipital decompression; ${ }^{2}$ there is variation in the use of duraplasty, cervical laminectomy, cerebellar tonsil cauterization, and/or division of the arachnoid membrane..$^{2,3,16}$ Surgical planning for congenital CM-I, however, should take into consideration more than cerebellar tonsil herniation. Ventral brainstem compression associated with congenital CM-I from basilar invagination has a reported incidence of $4 \%-31 \%$, predominantly in the pediatric population. , $, 4,5,13$ Posterior decompression with CM-I patients with coexisting basilar invagination involves a higher late complication rate even if the anterior component is not initially symptomatic if there is postdecompression cranial settling. ${ }^{4}$ In rare cases of symptomatic postdecompression cranial settling, some have advised initial preservation of the C-2 lamina or occipital-C1-2 fusion with subsequent transoral resection of the odontoid if cervicomedullary indentation persists. ${ }^{14}$ Our data suggest that an element of basilar invagination may be more frequent in the CM-I population based on the acquired measurements, which would be an important preoperative consideration when discussing the potential for surgical complications or need for additional operative intervention.

The limitations of this study include an element of sex bias in the control group, which is predominately male, and the CM-I group, which is predominately female. We believe this bias was mitigated by performing sex-specific comparisons at the expense of decreasing the size of the control and CM-I groups. The differences in imaging modality between the control and CM-I groups also represent a limitation of this study. However, both CT and MRI demonstrate the relevant anatomy when making CCJ measurements. The dentocentral synchondrosis and the osseous margins are better seen on CT, which may have contributed to the differences in measurements between CT and MRI. While MRI demonstrates superior soft tissue differentiation posterior to the odontoid, we believe that high-quality $\mathrm{CT}$ is adequate in the determination of retroodontoid soft-tissue thickness as the density difference between the posterior longitudinal ligament and adjacent CSF is readily appreciated (Fig. 3). At our institution, MRI is the standard modality for the preoperative evaluation of patients with CM-I. Although CT delineates the osseous anatomy of the CCJ for operative planning, the superb softtissue resolution of MRI is essential to evaluate tonsillar ectopia, syringomyelia, CCJ obstruction, and cervicomedullary compression, and the potential for resulting edema related to retroodontoid soft-tissue or odontoid retroflexion. 


\section{Conclusions}

The data in this study suggest that sex-specific differences exist with respect to CCJ measurements, as women showed greater odontoid retroflexion and shorter odontoid processes, and there was no significant difference in posterior odontoid inclination/retroflexion in the adult CM-I population when compared with normal, sex-specific controls. Apparent differences in posterior odontoid inclination in these groups are more likely due to relative skull base hypoplasia, which is known to occur in the CM-I population and due to a greater amount of peri-odontoid soft tissue. Odontoid angulation measurements are only a corollary to other imaging and clinical features in the preoperative evaluation of symptomatic CM-I patients.

\section{References}

1. Cichetti DV, Sparrow SS: Developing criteria for establishing the interrater reliability of specific items: applications to assessment of adaptive behavior. Am J Ment Defic 86:127-137, 1981

2. Dyste GN, Menezes AH, VanGilder JC: Symptomatic Chiari malformations. An analysis of presentation, management, and long-term outcome. J Neurosurg 71:159-168, 1989

3. Goel A, Desai K: Surgery for syringomyelia: an analysis based on 163 surgical cases. Acta Neurochir (Wien) 142:293-302, 2000

4. Grabb PA, Mapstone TB, Oakes WJ: Ventral brain stem compression in pediatric and young adult patients with Chiari I malformations. Neurosurgery 44:520-528, 1999

5. Hwang SW, Heilman CB, Riesenburger RI, Kryzanski J: C1$\mathrm{C} 2$ arthrodesis after transoral odontoidectomy and suboccipital craniectomy for ventral brain stem compression in Chiari I patients. Eur Spine J 17:1211-1217, 2008

6. Imperato A, Seneca V, Cioffi V, Colella G, Gangemi M: Treatment of Chiari malformation: who, when and how. Neurol Sci 32 (Suppl 3):S335-S339, 2011

7. Iskandar BJ, Oakes WJ: Chiari malformations and syringomyelia, in Albright L, Pollack I, Adelson P (eds): Principles and Practice of Pediatric Neurosurgery. New York: Thieme Medical, 1999, pp 165-187

8. Khaleel ZL, Besachio DA, Bisson EF, Shah LM: Estimation of odontoid process posterior inclination, odontoid height, and $\mathrm{pB}-\mathrm{C} 2$ line in the adult population. J Neurosurg Spine 20:172-177, 2014

9. Koenigsberg RA, Vakil N, Hong TA, Htaik T, Faerber E, Maiorano T, et al: Evaluation of platybasia with MR imaging. AJNR Am J Neuroradiol 26:89-92, 2005

10. Massimi L, Peppucci E, Peraio S, Di Rocco C: History of Chiari type I malformation. Neurol Sci 32 (Suppl 3):S263S265, 2011

11. Menezes AH: Primary craniovertebral anomalies and the hindbrain herniation syndrome (Chiari I): data base analysis. Pediatr Neurosurg 23:260-269, 1995

12. Milhorat TH, Chou MW, Trinidad EM, Kula RW, Mandell $\mathrm{M}$, Wolpert C, et al: Chiari I malformation redefined: clinical and radiographic findings for 364 symptomatic patients. Neurosurgery 44:1005-1017, 1999

13. Milhorat TH, Nishikawa M, Kula RW, Dlugacz YD: Mecha- nisms of cerebellar tonsil herniation in patients with Chiari malformations as guide to clinical management. Acta Neurochir (Wien) 152:1117-1127, 2010

14. Pang D, Thompson DN: Embryology and bony malformations of the craniovertebral junction. Childs Nerv Syst 27:523-564, 2011

15. Patel NP, Wright NM, Choi WW, McBride DQ, Johnson JP: Forestier disease associated with a retroodontoid mass causing cervicomedullary compression. J Neurosurg 96 (2 Suppl):190-196, 2002

16. Pollack IF, Pang D, Albright AL, Krieger D: Outcome following hindbrain decompression of symptomatic Chiari malformations in children previously treated with myelomeningocele closure and shunts. J Neurosurg 77:881-888, 1992

17. Salunke P, Sura S, Futane S, Aggarwal A, Khandelwal NK, Chhabra R, et al: Ventral compression in adult patients with Chiari 1 malformation sans basilar invagination: cause and management. Acta Neurochir (Wien) 154:147-152, 2012

18. Smoker WR, Khanna G: Imaging the craniocervical junction. Childs Nerv Syst 24:1123-1145, 2008

19. Streiner DL, Norman GR: Health Measurement Scales: A Practical Guide to Their Development and Use. New York: Oxford University Press, 2008, pp 111-122

20. Tubbs RS, Wellons JC III, Blount JP, Grabb PA, Oakes WJ: Inclination of the odontoid process in the pediatric Chiari I malformation. J Neurosurg 98 (1 Suppl):43-49, 2003

21. Young WF, Boyko O: Magnetic resonance imaging confirmation of resolution of periodontoid pannus formation following $\mathrm{C} 1 / \mathrm{C} 2$ posterior transarticular screw fixation. J Clin Neurosci 9:434-436, 2002

22. Zeidman SM, Ducker TB: Rheumatoid arthritis. Neuroanatomy, compression, and grading of deficits. Spine (Phila Pa 1976) 19:2259-2266, 1994

\section{Disclosure}

The corresponding author is a military service member. This work was prepared as part of his official duties. Title 17, USC, section 105 provides that "Copyright protection under this title is not available for any work of the United States Government." Title 17, USC, section 101 defines a US Government work as a work prepared by a military service member or employee of the US Government as part of that person's official duties. The views expressed in this article are those of the authors and do not necessarily reflect the official policy or position of the Department of the Navy, Department of Defense, or the US Government.

\section{Author Contributions}

Conception and design: all authors. Acquisition of data: Besachio, Shah. Analysis and interpretation of data: Besachio, Shah. Drafting the article: Besachio, Khaleel. Critically revising the article: all authors. Reviewed submitted version of manuscript: all authors. Statistical analysis: Besachio, Shah. Administrative/ technical/material support: Besachio. Study supervision: Besachio, Shah.

\section{Correspondence}

David A. Besachio, Department of Radiology, US Naval Medical Center Portsmouth, 620 John Paul Jones Cir., Portsmouth, VA 23708. email: david.besachio@gmail.com. 